\title{
URBAN MOBILITY STRATEGIES TO IMPROVE LOCAL AIR QUALITY: CASE STUDY OF LISBON, PORTUGAL
}

\author{
DIOGO LOPES ${ }^{1}$, JOANA FERREIRA $^{1}$, SANDRA RAFAEL $^{1}$, PATRICIA BAPTISTA ${ }^{2}$, MARTA FARIA ${ }^{3}$, \\ NUNO CANHA ${ }^{1,4}$, SUSAN MARTA ALMEIDA ${ }^{4} \&$ MARINA ALMEIDA-SILVA $^{4,5}$ \\ ${ }^{1}$ Department of Environment and Planning, CESAM, University of Aveiro, Portugal \\ ${ }^{2} \mathrm{IN}+$ Center for Innovation, Technology and Policy Research, Universidade de Lisboa, Portugal \\ ${ }^{3}$ LAETA, IDMEC - Instituto Superior Técnico, Universidade de Lisboa, Portugal \\ ${ }^{4}$ Centre for Nuclear Sciences and Technologies (C2TN), University of Lisbon, Portugal \\ ${ }^{5}$ H\&TRC - Health \& Technology Research Center, Instituto Politécnico de Lisboa, Portugal
}

\begin{abstract}
Particulate matter concentrations are still exceeding the European air quality limit values, mainly in the urban areas where a large part of the population lives. Despite the implementation of several policies and measures to reduce the atmospheric emissions from road transport, this activity still has high influence in the air quality of the European cities. The main purpose of this study was to assess the potential of urban mobility strategies to reduce the particulate matter concentrations over the main avenue of Moscavide (a parish within the municipality of Loures, very close to the city of Lisbon, Portugal). The proposed strategies were evaluated by applying an air quality modelling system with a high spatial resolution. The results showed a slight air quality improvement (up to $0.9 \mu \mathrm{g} . \mathrm{m}^{-3}$ ) for the tested scenarios. However, complementary studies are still necessary to provide a better understanding of the most efficient urban mobility strategies to be applied over the study area.

Keywords: PM10, road transport, urban mobility strategies, air quality modelling.
\end{abstract}

\section{INTRODUCTION}

Despite the efforts on reducing particulate matter (PM) atmospheric emissions, the European population lives in urban areas where particles levels with an aerodynamic equivalent diameter less than or equal to $10 \mu \mathrm{m}\left(\mathrm{PM}_{10}\right)$ exceed quite often the air quality limit values, [1] with severe implications for human health [2].

Road transport is one of Europe's main sources of $\mathrm{PM}_{10}$ [1]. To reduce the atmospheric emissions from this sector, in the last decades, several policies and measures have been implemented such as: (i) definition of European emission standards (e.g. Euro 5 and Euro 6); (ii) modifications in the fuel specifications (e.g. reduction of sulphur content); (iii) development of alternative fuels (e.g. compressed natural gas (CNG)) and devices for treatment of exhaust gases (e.g. diesel particulate filter) [3]; (iv) encouraging a shift among transport modes; (v) land use planning to ensure sustainable transport facilities; and (vi) improving public transport and procurement [1].

The ongoing REMEDIO project (regenerating mixed-use Mediterranean (MED) urban communities congested by traffic through Innovative low carbon mobility solutions, part of Interreg MED Program and co-funded by European Regional Development Fund (ERDF)) aims to strength the capacity of cities to use low carbon transport systems and include them in their mobility plans by testing existing mobility solutions, through an assessment tool and participatory governance schemes that result in an operational path replicable by other MED urban areas with different city sizes. This work is part of this project and aims to evaluate the potential of urban mobility strategies to reduce $\mathrm{PM}_{10}$ levels over the main avenue of Moscavide located in Loures municipality (close to Lisbon, Portugal). The baseline case and proposed strategies were evaluated using an air quality modelling system with high temporal and spatial resolution. In addition, data collected in field campaigns conducted for an autumn 
period, covering traffic counts and air quality monitoring, were used to estimate road transport emissions and to select the simulation period, respectively.

The paper is organised as follow: in Section 2, the air quality modelling setup and configuration are described in detail. Section 3 and Section 4 focus in the simulation episode selection and urban mobility strategies results, respectively. Finally, in Section 5, the main conclusions are presented.

\section{AIR QUALITY MODELLING SETUP AND CONFIGURATION}

To evaluate the potential of mobility scenarios to improve the air quality in the main avenue of Moscavide, an adequate model able to simulate atmospheric concentrations at street level was selected. The Computational Fluid Dynamic (CFD) model VADIS [4], [5] developed at the University of Aveiro is suitable for the present case study. This model is composed by the FLOW and DISPER modules. The FLOW calculates the wind, pressure, turbulence kinetic energy, turbulent viscosity and temperature three-dimensional (3D) while the DISPER computes the 3D air pollution concentrations using the wind field estimated by the FLOW. The main input data of the VADIS model are the local meteorological conditions (wind speed, wind direction and temperature), road transport emissions and buildings volumetry (buildings coordinates and height).

The VADIS was applied over the main avenue of Moscavide with a domain of $536 \times 536 \times 70$ (length $\times$ width $\times$ height) and a grid resolution of $3 \times 3 \times 3 \mathrm{~m}^{3}$. The study case consists in one narrow way road of about 400 meters surrounded by buildings with less than 14 meters of height and, consequently, has unfavourable air pollution dispersion conditions. Fig. 1 shows the buildings and road segments (1-5) over the study area.

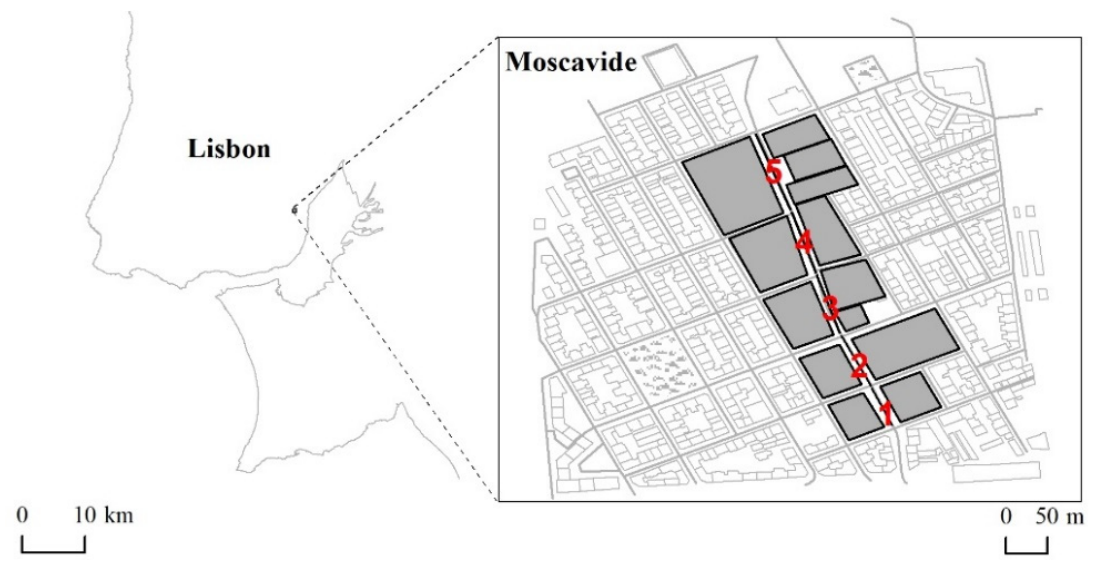

Figure 1: Application area of urban mobility strategies with the buildings and road segments considered.

The meteorological parameters can be obtained either from measurements at a meteorological station or from a meteorological model. For this work the Advanced Research Weather Research and Forecasting model (WRF-ARW) (v.3.7.1) [6] was considered. This model has been extensively used in Portugal and worldwide [7]-[9]. It provides meteorological fields for the region of interest by applying a nesting approach, from global to regional scales, covering the study area. In this work, it was applied with the following nested domains: domain 1 (D1) with a spatial resolution of $125 \mathrm{~km}$, covering the Europe and 
part of North Africa; D2 with a spatial resolution of $25 \mathrm{~km}$, comprising Iberian peninsula; and D3 with a spatial resolution of $5 \mathrm{~km}$, covering the Portuguese region. The global meteorological fields from the National Center for Environmental Prediction, with $1 \times 1^{\circ}$ $\left(\approx 10 \times 10 \mathrm{~km}^{2}\right)$ of horizontal resolution and 6 hours of temporal resolution, were used to provide initial and boundary conditions for the coarse meteorological domain (D1). The model physical configuration was defined according to previous WRF model simulations over the Portuguese region [10], [11].

The Transport Emission Model for line sources (TREM) [12] was used to estimate road transport emissions for the baseline case and urban mobility strategies. Road traffic counts were used to obtain the traffic flow for the study area. The vehicle fleet composition (vehicle categories and classes) was defined using statistical data from Statistical National Institute (INE) and the Portuguese Automobile Trade Association (ACAP) [13], [14]. For the urban mobility strategies, four scenarios were created and tested over the study area. Scenario 1: vehicles below the Euro 3 emission standard were replaced by newer cars (Euro 4, 5 and 6); Scenario 2: diesel used by the buses was replaced by compressed natural gas (CNG); Scenario 3: maximum vehicle speed limited was increased to $35 \mathrm{~km} . \mathrm{h}^{-1}$; and Scenario 4: the road traffic was closed in the road segment 5 (Fig. 1). It should be noted that the road traffic flow was kept the same in all tested scenarios, except for the Scenario 4 where the road segment 5 was closed (without traffic flow). The scenarios of this work have been tested and implemented worldwide, showing for that, their applicability and economic sustainability over the case study [12], [15].

The buildings 3D coordinates input data were provided by the OpenStreetMap dataset [16] and the buildings' shapes were defined according to proximity and geometry criteria (building in 2D are represented in Fig. 1). The building heights were estimated based on number of floors and considering 2.8 meters per floor.

\section{SIMULATION EPISODE SELECTION}

During November 2016, air quality monitoring and traffic count campaigns over the case study area were conducted. With the main purpose of selecting the hourly episode for the air quality modelling application, the daily profile for the measured $\mathrm{PM}_{10}$ levels and traffic flow in the area of interest were analysed (see Fig. 2). The wind speed and wind direction from WRF-ARW cells, located over the modelling domain, for the experimental campaigns were also analysed (Fig. 2).
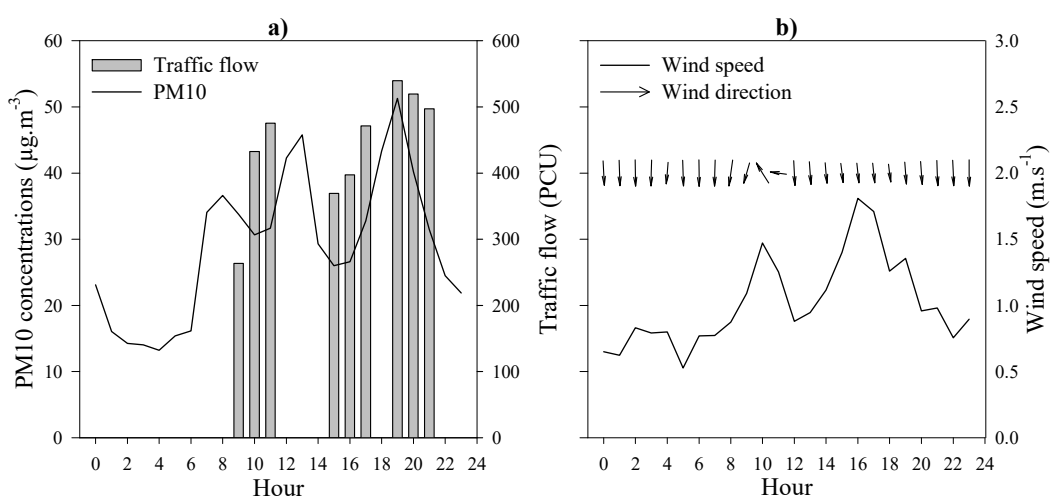

Figure 2: (a) Hourly values of $\mathrm{PM}_{10}$ concentrations and traffic flow in the case study; (b) Hourly wind fields at the inlet boundaries of the air quality modelling system. 
During the experimental campaign, the $\mathrm{PM}_{10}$ levels showed variations consistent with changes in road traffic flow. Three air pollution peaks in the morning (at 9 am), at midday $(1 \mathrm{pm})$ and evening rush hours (at $7 \mathrm{pm}$ ) were registered. The highest $\mathrm{PM}_{10}$ concentrations $\left(51 \mu \mathrm{g} \cdot \mathrm{m}^{-3}\right)$ were recorded at $7 \mathrm{pm}$ when the wind blew from north and wind speed was about $1.4 \mathrm{~m} . \mathrm{s}^{-1}$. The identification of emission sources of the study area shows that soil, road transport exhaust emissions, non-exhaust emissions, sea salt and fuel-oil contribute to about $36.3,9.9,24.8,17.2$ and $11.9 \%$ of the measured PM concentrations during the experimental campaign, respectively [17]. Values between 10 and $25 \mu \mathrm{g} . \mathrm{m}^{-3}$ were obtained for the off-peak period $(0 \mathrm{am}-8 \mathrm{am})$ and the registered $\mathrm{PM}_{10}$ levels were lower than the European limit value (daily limit value is $50 \mu \mathrm{g} \cdot \mathrm{m}^{-3}$ ). Regarding the meteorological parameters, the wind speed ranged between 0.5 (at $5 \mathrm{am}$ ) and $1.8 \mathrm{~m} \cdot \mathrm{s}^{-1}$ (at $4 \mathrm{pm}$ ). The wind blew from southeast during late morning (10 am and $11 \mathrm{am}$ ) and for the remaining hours, the wind direction was mainly from the north.

According to the analysed air pollution levels, traffic flow and meteorological parameters, the hour of $7 \mathrm{pm}$ was selected for the air quality modelling application over the study area. In this sense, the evening rush hour (i.e. $7 \mathrm{pm}$ ) was selected for simulation, and thus, in the next sections, the simulated road transport emissions and air pollution levels correspond to the referred period. This analysis is quite important since that is the period when people are most exposed to air pollution, while they are driving, walking on the street or at home.

\section{URBAN MOBILITY STRATEGIES}

The urban mobility strategies were investigated considering as reference the baseline scenario (current situation). Two different approaches were used to provide this analysis: (i) road transport emissions by road segments to quantify the impact of measures in terms of $\mathrm{PM}_{10}$ emissions; (ii) mapping of the hourly $\mathrm{PM}_{10}$ levels differences between baseline and mitigation scenarios to understand the spatial variability of the air pollution concentrations.

Fig. 3 shows the road transport emissions by road segment (1-5), for the baseline case (Base case) and urban mobility scenarios (Scenario 1, 2, 3 and 4) for the study episode (7 pm).

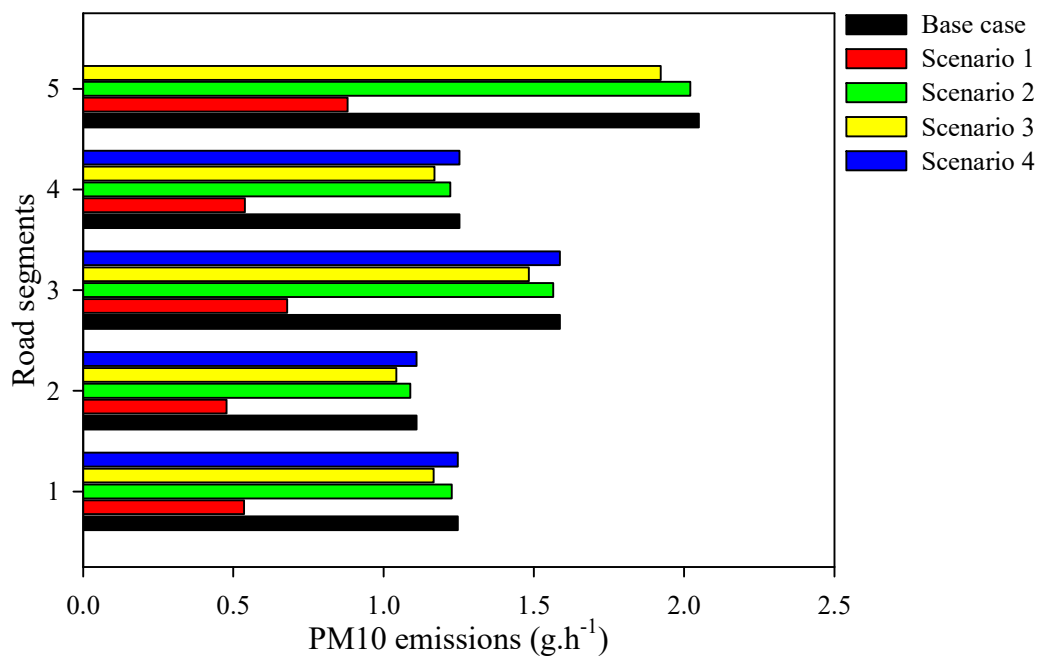

Figure 3: $\quad \mathrm{PM}_{10}$ emissions $\left(\mathrm{g} \cdot \mathrm{h}^{-1}\right)$, by road segment, for the baseline case and tested scenarios on evening rush hour $(7 \mathrm{pm})$. 
For the baseline case, the $\mathrm{PM}_{10}$ emissions vary in a range of 1.1 to 2.1 g.h $\mathrm{h}^{-1}$. Maximum values are obtained for the road segment located further north of the study area (road segment 5). The emissions of the remaining roads represent $50-80 \%$ of the total emissions of the main road. Analysing the emissions associated to each urban mobility strategy, the highest impacts are obtained for Scenarios 1 and 4 with a total reduction of about $4.1(57 \%)$ and 2.0 g.h h $^{-1}(28 \%)$, respectively. The replacement of the fuel used by buses (Scenario 2) and the increase of the maximum vehicle speed limits (Scenario 3) allow a total reduction of less than $0.5 \mathrm{~g} . \mathrm{h}^{-1}(6.4 \%)$. However, these results only allow to quantify the atmospheric emission impacts of the tested Scenarios. Concerning the air quality impacts, Fig. 4 presents the expected $\mathrm{PM}_{10}$ levels reduction (in $\mu \mathrm{g} \cdot \mathrm{m}^{-3}$ ) during the study episode $(7 \mathrm{pm})$.
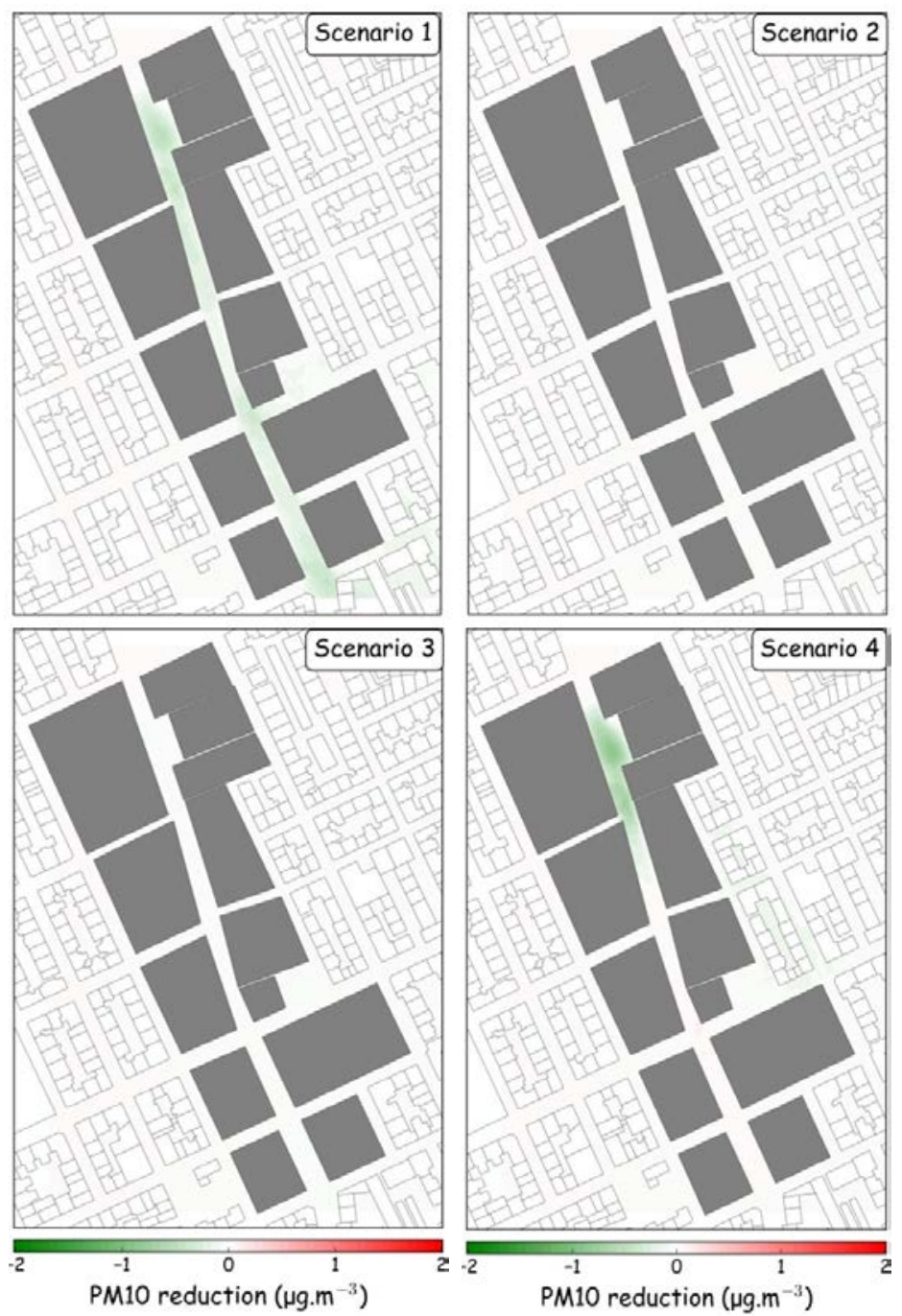

Figure 4: Air pollution reduction of $\mathrm{PM}_{10}$ levels based on the difference between each scenario and the baseline case. 
It can be observed that the implementation of Scenarios 1 and 2 reduce the $\mathrm{PM}_{10}$ concentrations up to $0.9 \mu \mathrm{g} . \mathrm{m}^{-3}$ over the study area. The highest air pollution decrease is recorded when the road segment 5 is closed. However, Scenario 1 reveals a larger reduction area with air quality improvements over the entire simulation domain (up to $0.5 \mu \mathrm{g} \cdot \mathrm{m}^{-3}$ ). For the remaining tested Scenarios, the replacement of the buses fuel (Scenario 2) and the increase of the maximum vehicle speed limit (Scenario 3) a slight decrease of $\mathrm{PM}_{10}$ concentrations is verified (less than $0.1 \mu \mathrm{g} . \mathrm{m}^{-3}$ ).

\section{CONCLUSIONS}

The main goal of this work was to evaluate the potential of urban mobility strategies to reduce the $\mathrm{PM}_{10}$ levels on a narrow street of an urban area. The proposed strategies were evaluated by the application of the CFD model VADIS, with high spatial and temporal resolution to different scenarios. The TREM was used to estimate road transport emissions for the baseline case, based on traffic counts performed in the study area, and for the proposed scenarios. Air quality monitoring and traffic count campaigns for an autumn period shown that the highest $\mathrm{PM}_{10}$ concentrations are recorded on evening rush hours (at $7 \mathrm{pm}$ ) when the wind blows from north and the wind speed is about $1.4 \mathrm{~m} \cdot \mathrm{s}^{-1}$. The tested urban mobility strategies showed that the highest reductions of $\mathrm{PM}_{10}$ concentrations are obtained when the Euro 3 vehicles are banned and the road segment with the largest traffic flow is closed. However, complementary studies considering different scenarios and the influence of the non-exhaust emission from the road traffic (this source represents about $25 \%$ of the measured $\mathrm{PM}_{10}$ concentrations in the study area) is needed to provide a better understanding of the most efficient urban mobility strategies.

\section{ACKNOWLEDGEMENTS}

This work was supported by the European Regional Development Fund (ERDF) through the Interreg MED project REMEDIO (Ref. 862). Thanks are due for the financial support to CESAM (UID/AMB/50017/2019), to FCT/MCTES through national funds, and the co-funding by the ERDF, within the PT2020 Partnership Agreement and Compete 2020.

\section{REFERENCES}

[1] European Environmental Agency (EEA), Air quality in Europe - 2018. Report, no. 12. 2018.

[2] Costa, S. et al., Integrating health on air quality assessment-Review report on health risks of two major european outdoor air pollutants: $\mathrm{PM}_{\text {and }} \mathrm{NO}_{2}$. J. Toxicol. Environ. Heal. Part B, 17(6), pp. 307-340, 2014.

[3] Lopes, D., Determinação de Fatores de Emissão de Gases de Exaustão de Veículos, Universidade de Aveiro, 2013.

[4] Rafael, S., Vicente, B., Rodrigues, V., Miranda, A.I., Borrego, C. \& Lopes, M., Impacts of green infrastructures on aerodynamic flow and air quality in Porto's urban area. Atmos. Environ., 190(July), pp. 317-330, 2018.

[5] Amorim, J.H., Rodrigues, V., Tavares, R., Valente, J. \& Borrego, C., CFD modelling of the aerodynamic effect of trees on urban air pollution dispersion. Sci. Total Environ., 461-462, pp. 541-551, 2013.

[6] Skamarock, W.C. et al., A Description of the Advanced Research WRF Version 3, 2008.

[7] Lopes, D., Ferreira, J., Hoi, K., Miranda, A.I., Yuen, K.V. \& Mok, K.M., Weather research and forecasting model simulations over the Pearl River Delta Region. Air Qual. Atmos. Heal., 12, pp. 115-125, 2019. 
[8] Evans, J.P., Ekstrom, M. \& Ji, F., Evaluating the performance of a WRF physics ensemble over South-East Australia. Clim. Dyn., 39(6), pp. 1241-1258, 2012.

[9] Rama Rao, Y.V., Alves, L., Seulall, B., Mitchell, Z., Samaroo, K. \& Cummings, G., Evaluation of the weather research and forecasting (WRF) model over Guyana. Nat. Hazards, 61(3), pp. 1243-1261, 2012.

[10] Carvalho, D., Rocha, A., Gómez-Gesteira, M. \& Santos, C., A sensitivity study of the WRF model in wind simulation for an area of high wind energy. Environ. Model. Softw., 33, pp. 23-34, 2012.

[11] Monteiro, A. et al., Air quality over Portugal in 2020. Atmos. Pollut. Res., 6(5), pp. 788-796, 2015.

[12] Li, X., Lopes, D., Mok, K.M., Miranda, A.I. \& Yuen, K.V., Development of a road traffic emission inventory with high spatial - temporal resolution in the world's most densely populated region - Macau. Environ. Monit. Assessmen, pp. 191-239, 2019.

[13] Associação Automóvel de Portugal (ACAP), Portugal Statistics for fleet composition, 2015, http://www.acap.pt/.

[14] Instituto Nacional de Estatística (INE), Statistics Portugal, 2011; CENSUS, 2011statistical data for Portugal, 2011, Online. http://censos.ine.pt.

[15] Duque, L. et al., Evaluating strategies to reduce urban air pollution. Atmos. Environ., 127(2), pp. 196-204, 2016.

[16] OpenStreetMap contributors, Planet dump; Data file from \$date of database dump\$, 2017, Online. https://planet.openstreetmap.org.

[17] Almeida, S.M., Manousakas, M.I., Diapouli, E. \& Eleftheriadis, K., Source apportionment in a street canyon : first approach within REMEDIO project. Presented at $5^{\text {th }}$ Iberian Meeting on Aerosol Science and Technology Jointly organised with IMPROVE LIFE13 ENV/ES/263, Barcelona, Spain, 2017. 